\title{
The dopamine D1-D2 receptor heteromer in striatal medium spiny neurons: evidence for a third distinct neuronal pathway in basal ganglia
}

\author{
Melissa L. Perreault ${ }^{1,2}$, Ahmed Hasbi ${ }^{1,2}$, Brian F. O'Dowd ${ }^{1,2}$ and Susan R. George ${ }^{1,2,3}$ * \\ ${ }^{1}$ Centre for Addiction and Mental Health, University of Toronto, Toronto, ON, Canada \\ ${ }^{2}$ Department of Pharmacology, University of Toronto, Toronto, ON, Canada \\ ${ }^{3}$ Department of Medicine, University of Toronto, Toronto, ON, Canada
}

\section{Edited by:}

Emmanuel Valjent, Université

Montpellier 1 and 2, France

Reviewed by:

Jean-Philippe R. Pin, Université de

Montpellier, France

John Q. Wang, University of

Missouri-Kansas City School of

Medicine, USA

*Correspondence:

Susan R. George, Department of Pharmacology, Medical Sciences Bldg., Room 4358, University of Toronto, 1 King's College Circle, Toronto, ON, Canada M5S 1 A8. e-mail:s.george@utoronto.ca

\begin{abstract}
Dopaminergic signaling within the basal ganglia has classically been thought to occur within two distinct neuronal pathways; the direct striatonigral pathway which contains the dopamine D1 receptor and the neuropeptides dynorphin (DYN) and substance $P$, and the indirect striatopallidal pathway which expresses the dopamine D2 receptor and enkephalin (ENK). A number of studies have also shown, however, that D1 and D2 receptors can coexist within the same medium spiny neuron and emerging evidence indicates that these D1/D2-coexpressing neurons, which also express DYN and ENK, may comprise a third neuronal pathway, with representation in both the striatonigral and striatopallidal projections of the basal ganglia. Furthermore, within these coexpressing neurons it has been shown that the dopamine D1 and D2 receptor can form a novel and pharmacologically distinct receptor complex, the dopamine D1-D2 receptor heteromer, with unique signaling properties. This is indicative of a functionally unique role for these neurons in brain. The aim of this review is to discuss the evidence in support of a novel third pathway coexpressing the D1 and D2 receptor, to discuss the potential relevance of this pathway to basal ganglia signaling, and to address its potential value, and that of the dopamine D1-D2 receptor heteromer, in the search for new therapeutic strategies for disorders involving dopamine neurotransmission.
\end{abstract}

Keywords: dopamine D1-D2 receptor heteromer, dynorphin, enkephalin, substance P, basal ganglia, striatonigral, striatopallidal
The striatum, consisting of the ventrally located nucleus accumbens (NAc) and dorsal caudate putamen (CP), is the largest component of a group of nuclei that comprise the basal ganglia and associated mesolimbic system. The neuronal makeup of the striatum consists predominantly ( $>90 \%$ ) of medium spiny neurons (MSNs), all of which express the inhibitory neurotransmitter GABA. However MSNs also exist as different subtypes, exhibiting discrete phenotypes that are characterized by their neuropeptide and dopamine receptor content, and which are dependent upon the neuronal pathways to which they are localized.

At least two major neuronal pathways in the basal ganglia have been identified (Figure 1). The MSNs of the striatonigral pathway, also called the "direct" pathway, project to substantia nigra reticulata $(\mathrm{SNr})$ and the internal segment of the globus pallidus (GPi; analogous to rat entopeduncular nucleus, EPN). These neurons are characterized by the expression of the neuropeptides dynorphin (DYN) and substance P (SP), as well as the dopamine D1 receptor (D1R). In contrast, the neurons of the striatopallidal "indirect" pathway, projecting to the external segment of GP (GPe; analogous to rat GP), express the neuropeptide enkephalin (ENK) and the dopamine D2 receptor (D2R; Gerfen et al., 1990). These two pathways work in concert to regulate thalamic output.

Traditional thinking has depicted the D1R and D2R as being segregated to these discrete populations of striatal MSNs. However, this idea has been becoming more difficult to reconcile as increasing evidence, both functional and neuroanatomical, indicates that D1R and D2R can be coexpressed in a subpopulation of striatal MSNs. Furthermore, the recent identification of a novel dopamine receptor complex in striatum, the dopamine D1-D2 receptor heteromer, also suggests that these coexpressing MSNs may have unique functional characteristics that are distinct from those neurons that exhibit dopamine receptor segregation. In this review we describe the evidence showing D1R/D2R coexpression in a subset of striatal MSNs and discuss their unique functional role in basal ganglia and mesolimbic neurotransmission. We put forth that these D1R/D2R-coexpressing MSNs represent a third functional striatal pathway with significant physiological relevance.

\section{DOPAMINE D1R AND D2R ARE FUNCTIONALLY LINKED}

Numerous reports have documented opposing effects of the Gscoupled D1R and Gi/o-coupled D2R on biological processes such as adenylyl cyclase activity and cAMP formation (Hyttel, 1978; Onali et al., 1985) and striatal acetylcholine release (DeBoer and Abercrombie, 1996). However, it has also been demonstrated that the concomitant activation of both D1R and D2R is essential to achieve certain other behavioral, biochemical, and electrophysiological effects. For instance, past studies have shown 


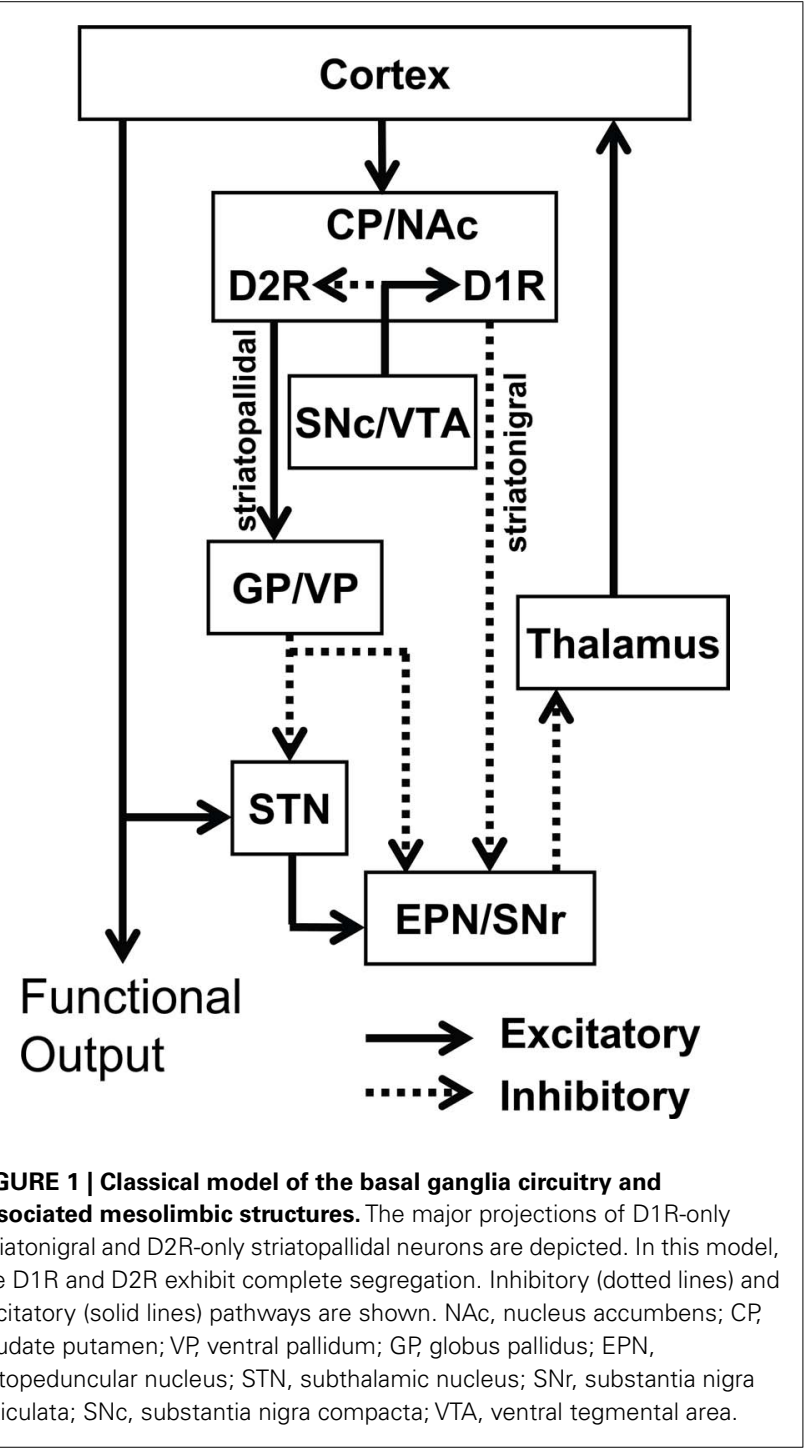

coactivation of the D1R and D2R as being necessary for maximal stereotyped and locomotor behavior (Walters et al., 1987; White et al., 1988; DeBoer and Abercrombie, 1996), and more recently it was reported that to evoke neural and behavioral phenotypes of cocaine sensitization, both D1R and D2R stimulation is required (Capper-Loup et al., 2002). Similarly, at a cellular level, combined administration of specific D1R and D2R agonists was shown to potentiate immediate early gene expression (LaHoste et al., 1993; Keefe and Gerfen, 1995). For example, while the systemic administration of a dopamine D1R agonist induced the expression of $\mathrm{c}$-fos and zif268 in the dopamine-depleted striatum, and a D2R agonist decreased zif268 expression, both agonists together significantly enhanced gene expression compared to the D1R agonist alone (Keefe and Gerfen, 1995). Electrophysiological evidence has also demonstrated that simultaneous administration of D1R and D2R agonists could synergistically inhibit the neuronal activity of NAc neurons (White and Wang, 1986; Hu et al., 1990), and restoration of long-term depression of synaptic transmission following dopamine depletion occurred by dopamine administration or coadministration of specific D1R and D2R agonists but not by either selective agonist alone (Calabresi et al., 1992).

Although the mechanisms for the D1R and D2R interaction have been suggested to occur by receptor activation on discrete neurons (Gerfen et al., 1995; LaHoste et al., 2000), or changes in D2R-mediated cholinergic interneuron activity with subsequent impact on D1R-expressing striatonigral neuronal transmission (Di Chiara et al., 1994), in many studies the mechanisms were not clearly understood. However, an interaction between the receptors occurring within the same cell may have been involved in some instances. For example, single MSN-MSN connections in neonatal striatal cultures have been reported to exhibit modulation by both D1R and D2R agonists (Geldwert et al., 2006) and the selective activation of D1R or D2R in single striatal neurons differentially modulated tetrodotoxin-sensitive sodium channels (Aizman et al., 2000). The synergistic potentiation of the arachidonic acid release by coadministration of D1R-selective and D2R-selective agonists has also been observed in cells expressing both receptors (Piomelli et al., 1991).

\section{NEUROANATOMICAL EVIDENCE FOR D1R AND D2R COLOCALIZATION}

Given the functional linkage between D1R and D2R, neuroanatomical studies began to address the question of dopamine receptor segregation and many of these studies have now shown, both at the mRNA level and the protein level, that D1R and D2R coexist in a fraction of striatal MSNs. In situ hybridization studies examining D1R and D2R mRNA in serial rat brain striatal sections have shown overlap of D1R and D2R transcript expression in the same neurons (Meador-Woodruff et al., 1991; Lester et al., 1993) and double in situ hybridization has been used to report colocalization of D1R and D2R mRNA in some striatal neurons in primate (Aubert et al., 2000). D1R/D2R mRNA coexistence was also reported using single cell reverse transcription PCR in neonatal neurons (Surmeier et al., 1992, 1996) and immunolabeling has been a widely used tool for visualizing striatal D1R/D2R coexpression at the protein level in both neonatal striatal cultures (Shetreat et al., 1996; Wong et al., 1999; Aizman et al., 2000; Hasbi et al., 2009) and in adult brain slices (Lee et al., 2004; Deng et al., 2006; Hasbi et al., 2009; Perreault et al., 2010).

It had been noted that while neurons expressing solely mRNA for the D1R or D2R were abundant in SP or ENK mRNA respectively, neurons containing mRNA for both D1R and D2R expressed both SP and ENK mRNAs (Surmeier et al., 1996). Similarly, in a recent study by Perreault et al. (2010), using highly validated antibodies, it was shown that the D1R and D2R were expressed exclusively in neurons containing both DYN and ENK. Although a small minority of DYN/ENK neurons did not express D1R or $\mathrm{D} 2 \mathrm{R}$, these findings indicated that SP/DYN-ENK coexpression could be a useful marker for identifying neurons coexpressing $\mathrm{D} 1 \mathrm{R}$ and $\mathrm{D} 2 \mathrm{R}$. Interestingly, unlike the controversy surrounding the localization of D1R and D2R, SP/DYN-ENK coexpression in striatal neurons has been widely accepted, and overlap of SP/DYN and ENK mRNA or protein in a proportion of striatal projection neurons has been reported for a number of species (Penny et al., 1986; Gerfen and Young, 1988; Anderson and Reiner, 1990; Besson 
et al., 1990; Chen et al., 1998; Stefani et al., 1998; Reiner et al., 1999; Vorobjev et al., 2000; Wang et al., 2006, 2007; Perreault et al., 2010).

\section{Drd1a-EGFP AND Drd2-EGFP BAC TRANSGENIC MICE}

In recent years, technological advances have provided novel approaches for assessing dopamine receptor colocalization. Enhanced green fluorescent protein (EGFP)-tagged promoter elements of D1R and D2R in bacterial artificial chromosome (BAC) transgenic mice is one such method, and has been used to quantify the proportion of striatal neurons expressing the receptors within the striatonigral and striatopallidal pathways (Valjent et al., 2009). In an elegant study by Bertran-Gonzalez et al. (2008) it was reported that while the majority of D1R and D2R were segregated to these discrete pathways, an estimated $17 \%$ of NAc shell MSNs exhibited receptor colocalization with $\sim 6 \%$ D1R/D2R coexpression in CP. Although there has been doubt as to the reliability of BAC transgenic mice in providing an accurate representation of dopamine receptor expression due to unlabeled neurons (Shuen et al., 2008), another group was able to show that $100 \%$ of MSNs in these mice expressed D1R, D2R or both (Matamales et al., 2009) and that the proportion of neurons showing coexpression were similar to that observed in the Bertran-Gonzalez study.

Fluorescence activated cell sorting (FACS), another relatively novel method, is used for sorting a heterogeneous mixture of biological cells and is based upon the fluorescent characteristics of each cell. Essentially, this method employs the fluorescent properties of the neurons in the BAC transgenic $d r d 1 a$-EGFP or drd2-EGFP mice to purify D1R-expressing and D2R-expressing MSNs, and is often used to assess specific characteristics of these two neuronal subtypes. The quality of the purification process can then be verified by assessing mRNA content of the each sample. Using this process, it was recently shown that while purified D1Rpositive neurons from whole striatum displayed enrichment of D1R mRNA, D2R mRNA was also evident, albeit in small amounts (Lobo et al., 2010). Similarly, D2R-positive neurons also displayed evidence of minimal D1R mRNA being present. In addition, using BAC transgenic mice with Cre recombinase being driven by the D1R or D2R promoters, and using double immunofluoresence to stain for Cre and ENK, this group also showed that a fraction of striatal D1R-expressing neurons were also positive for ENK.

\section{FUNCTIONAL RELEVANCE OF D1R/D2R-COEXPRESSING NEURONS}

Although the existence of D1R- and D2R-coexpressing MSNs is now generally accepted, little is yet known about the functional relevance of these neurons, most likely as a result of the methodological difficulties attempting to isolate them. However, it has been shown that while all MSNs express mRNA for the GluA1 and GluA2 subunits of the AMPA receptor (Chen et al., 1998; Stefani et al., 1998; Vorobjev et al., 2000), only SP/ENK neurons preferentially express mRNA for GluA3 (Stefani et al., 1998) a finding which the authors posited as being suggestive of distinctive postsynaptic glutamatergic mechanisms in the neurons. A role in neurotransmission is supported by evidence documenting that striatal projection neurons coexpressing D1R and D2R or $\mathrm{SP}$ and ENK terminate in a number of regions including GP and EPN (GPi), as well as substantia nigra and ventral tegmental area
(Deng et al., 2006; Wang et al., 2006, 2007), two regions rich in dopamine cell bodies. In addition, a region-specific distribution of D1R/D2R-DYN/ENK neurons throughout the rat basal ganglia and mesolimbic pathway has been reported, being present in NAc (Figure 2) and CP, as well as GP and ventral pallidum and EPN (Perreault et al., 2010). Specifically, it was estimated that the fraction of D1R-expressing neurons also expressing the D2R in NAc core and shell was $\sim 25 \%$ and $\sim 35 \%$ respectively, whereas in $\mathrm{CP}$ the percentage was much lower being only $\sim 7 \%$. In GP and $\mathrm{VP}$, while the total number of D1R neurons was quite low compared to other regions, a high percentage of these neurons $(\sim 60 \%$ and $\sim 30 \%$ ) also contained D2R. Similarly, in EPN the fraction of D1R containing neurons also expressing the D2R was relatively high ( $50 \%)$.

In basal ganglia, the coexpression of D1R and D2R has been shown to occur both within neuronal cell bodies and selectively at presynaptic, but not postsynaptic terminals, as evidenced by $\mathrm{D} 1 \mathrm{R}$ and D2R coexpression with the presynaptic marker synaptophysin, but not the postsynaptic marker PSD-95 (Perreault et al., 2010). Presynaptic colocalization of D1R and D2R on a fraction of varicosities has also been reported in neonatal striatal cultures (Wong et al., 1999; Geldwert et al., 2006; Mizuno et al., 2007) and electrophysiology studies have demonstrated that presynaptic dopamine receptors on MSN terminals could modulate GABAergic inhibitory postsynaptic currents (IPSCs; Delgado et al., 2000; Guzman et al., 2003; Geldwert et al., 2006). Interestingly, in one of these studies it was shown that while the D2R agonist quinpirole predominantly mediated inhibition of autaptic connections in MSNs, the D1R agonist SKF 38393 mediated either inhibition or facilitation (Geldwert et al., 2006). Although the authors did not directly address the seemingly discrepant effects of the D1R agonist on GABA transmission, it has been shown that SKF 38393 activates two biologically different signaling pathways, the cAMP pathway and phospholipase C (PLC)-phosphoinositide (PI) pathway (Undie and Friedman, 1990; Undie et al., 1994). Although it has been suggested that these two pathways are linked directly to D1R (Undie et al., 1994), it is now known that in MSNs that coexpress D1R and D2R, the receptors can form a heteromeric complex, the dopamine D1-D2 receptor heteromer, and it is this complex that directly activates the PLC-PI pathway (Lee et al., 2004; Rashid et al., 2007).

\section{THE DOPAMINE D1-D2 RECEPTOR HETEROMER}

Dopamine receptors exist as receptor homomers and can additionally form heteromeric receptor complexes that often exhibit pharmacological and cell signaling properties distinct from their constituent receptors (Lee et al., 2004; Rashid et al., 2007; Hasbi et al., 2009; So et al., 2009; Verma et al., 2010). A physical interaction between the D1R and D2R was first shown by coimmunoprecipitation from rat and human striatum (Lee et al., 2004), and was the first evidence of a dopamine heteromeric receptor complex in brain. These findings were later confirmed by fluorescence resonance energy transfer (FRET) a tool commonly used for the identification of receptor oligomers. Although first performed in cells (So et al., 2005; Dziedzicka-Wasylewska et al., 2006), quantitative FRET in situ has now been utilized to verify the presence of dopamine D1-D2 receptor heteromers in neonatal cultured rat 

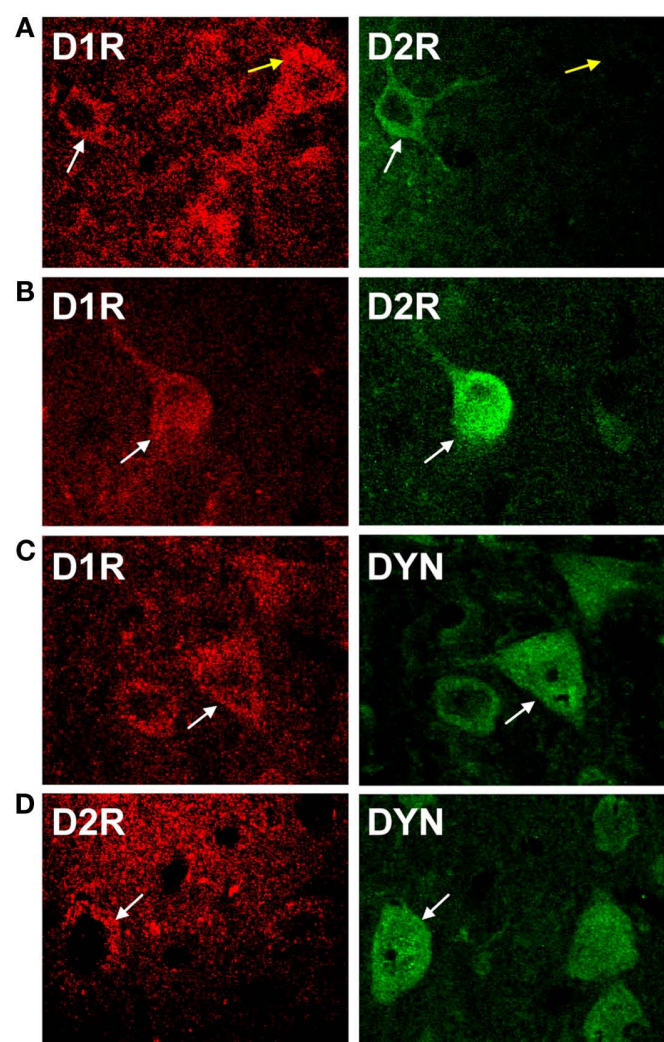

FIGURE 2 |The dopamine D1 and D2 receptor are colocalized with dynorphin and enkephalin in rat nucleus accumbens shell. $(A, B)$ Confocal images showing D1R and D2R colocalization with dynorphin (DYN) or
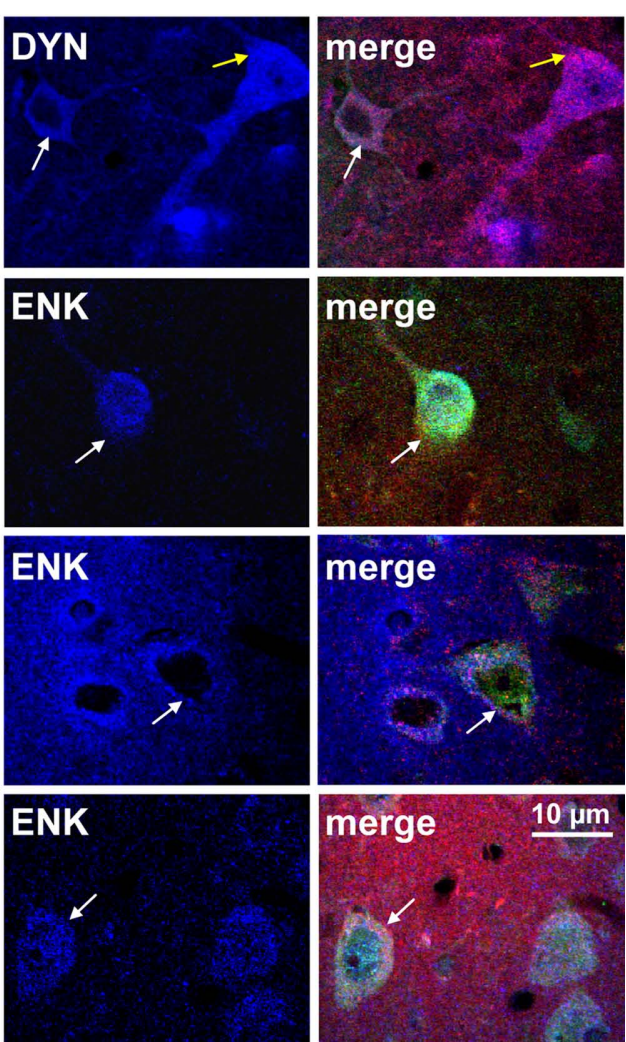

striatal neurons (Hasbi et al., 2009). Similarly, this method has now been employed to show, in vivo, that in adult rat NAc, CP (Hasbi et al., 2009; Perreault et al., 2010) and GP (Figure 3) the $\mathrm{D} 1 \mathrm{R}$ and $\mathrm{D} 2 \mathrm{R}$ existed in close $<50-100 \AA$ proximity indicative of $\mathrm{D} 1-\mathrm{D} 2$ receptor heteromerization. However, the propensity for striatal neurons to exhibit D1-D2 heteromers was regiondependent, with the majority (>90\%) of D1R/D2R-coexpressing neuronal cell bodies in NAc core and shell showing robust D1D2 heteromer formation, but only $\sim 25 \%$ of D1R/D2R neurons expressing the D1-D2 heteromer in CP (Perreault et al., 2010). This suggests that D1R and D2R can coexist as homomers in the same cell without forming heteromers. It was also shown in the neuropil of both NAc and CP the presence of D1-D2 heteromers at presynaptic terminals, a finding that suggests a possible involvement of synaptic D1-D2 receptor heteromer in GABA release in both regions.

The role of the D1-D2 heteromer in vivo is just beginning to be elucidated, however several lines of evidence have emerged implicating the complex as a potential therapeutic target in disorders involving elevated dopamine transmission, such as schizophrenia and drug addiction. Specifically, it has been postulated that abnormal regulation of calcium signaling may constitute the central dysfunction that is responsible for generating the psychopathology of schizophrenia (Lidow, 2003). Although the D1R and D2R have not been shown individually to be directly coupled to calcium enkephalin (ENK; white arrows). The D1R was also expressed individually with DYN (yellow arrows). (C,D) Neurons coexpressing DYN and ENK also expressed the D1R or the D2R (white arrows). signaling, coactivation of both receptors within the dopamine D1-D2 receptor heteromer by concurrent administration of D1R and D2R agonists, or the selective D1-D2 heteromer agonist SKF 83959, resulted in a novel Gq-PLC-linked increase in intracellular calcium release (Lee et al., 2004; Rashid et al., 2007). In addition, dopamine D1-D2 heteromer activation by SKF 83959 also induced striatal calcium calmodulin kinase II $\alpha$ (CaMKII $\alpha$ ) phosphorylation (Rashid et al., 2007; Ng et al., 2010) and brain-derived neurotrophic factor (BDNF) expression (Hasbi et al., 2009) two proteins that have been linked to schizophrenia (Weickert et al., 2003; Issa et al., 2010; Jindal et al., 2010; Novak and Seeman, 2010; Wong et al., 2010; Carlino et al., 2011). Finally, of particular relevance, an upregulation of striatal D1-D2 heteromeric activity was seen following repeated amphetamine treatment in rats and in human GP of patients with schizophrenia (Perreault et al., 2010). Given that amphetamine sensitization is often employed as an animal model for schizophrenia (Featherstone et al., 2007), but no common biochemical marker linking the two has previously been documented, it was inferred that the sensitized state of the D1-D2 heteromer may provide the first neuropharmacological correlate between increased dopamine neurotransmission and its functional consequence. As antipsychotics invariably also target the D1-D2 heteromer, these findings strongly suggest that further research examining the D1-D2 receptor heteromer as a potential drug target in schizophrenia is warranted. 

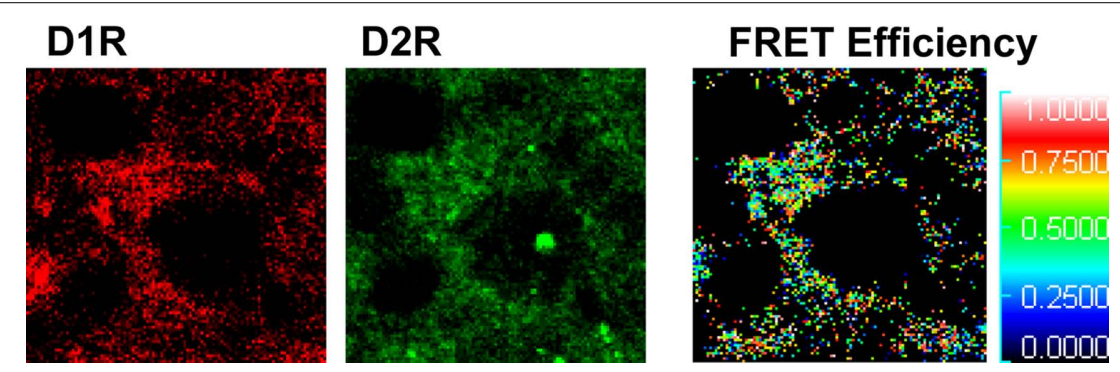

FIGURE 3 | Dopamine D1 and D2 receptors form D1-D2 receptor heteromers in rat globus pallidus. Fluorescence resonance energy transfer (FRET), using Alexa 488 and Alexa 350 was used to identify interactions between endogenous D1R and D2R in neurons of rat globus pallidus. An interaction between the D1R and D2R was evident, with a relatively high mean FRET Efficiency (efficiency of energy transfer between the donor and acceptor fluorophores) of $22 \%$. The receptor antibody-linked fluorophores were calculated to be in close proximity with a relative distance of $5-7 \mathrm{~nm}(50-70 \AA)$ indicative of D1-D2 receptor heteromer formation.
In addition to an involvement in schizophrenia, CaMKII and BDNF have also been shown to play a major role in cocaine addiction (Anderson et al., 2008; Lobo et al., 2010; McGinty et al., 2010; Wang et al., 2010). In one particularly compelling study, it was shown that cocaine reinstatement in rats depended upon an interaction between NAc dopamine and glutamate systems that was mediated by CaMKII (Anderson et al., 2008). More specifically, cocaine reinstatement increased activation of NAc shell CaMKII, which subsequently led to the phosphorylation of the GluA1 subunit of the AMPA receptor at Ser ${ }^{831}$, and increased cell-surface expression of GluA1-containing AMPA receptors. Interestingly, in contrast to the effects of acute selective activation of the D1-D2 heteromer in NAc, more prolonged selective activation has been reported to reduce total CaMKII levels in this region and additionally reduce phosphorylation of GluA1 at Ser ${ }^{831}$ (Perreault et al., 2010), a finding effectively linking the D1-D2 heteromer to the reward pathways of the brain.

\section{A CAUTIONARY NOTE ON THE USE OF DOPAMINE RECEPTOR AGONISTS}

It is now known that the agonist SKF 83959 directly activates calcium signaling via the dopamine D1-D2 receptor heteromer, but does not activate the D1R cAMP pathway or the Gi-coupled D2R (Rashid et al., 2007). Therefore findings from studies assessing the effects of SKF 83959 would not likely have been derived from functional interactions between D1R or D2R homomers within the same neuron, or between the D1R-expressing striatonigral and D2R-expressing striatopallidal populations of MSNs. However, for many years it was believed that the effects of the agonist SKF 83959 were mediated through its actions solely at the D1R. Reports had demonstrated that SKF 83959 had a substantial affinity for the D1R (Andringa et al., 1999; Neumeyer et al., 2003), however the physiological actions of SKF 83959 at the D1R were the subject of much debate as the drug exhibited antagonistic properties on adenylyl cyclase activity (Arnt et al., 1992; Andringa et al., 1999; Jin et al., 2003) yet mimicked certain behavioral characteristics of D1R agonism such as grooming or the induction of circling behavior (Deveney and Waddington, 1995; Gnanalingham et al., 1995; Waddington et al., 1995; Zhen et al., 2005; Perreault et al., 2010). However, SKF 83959 was also linked to PLC activation and PI hydrolysis in brain (Panchalingam and Undie, 2001; Jin et al.,
2003; Zhen et al., 2005; Rashid et al., 2007), a pathway that had also been observed to be induced with a number of other D1R agonists in brain tissue (Undie et al., 1994; Desai et al., 2005) but, interestingly, not in cells expressing only the D1R (Lin et al., 1995).

Given the ability of D1R agonists to directly induce PI hydrolysis in brain, but not in cells expressing solely the D1R, this suggests that D1R agonists that stimulate this pathway do so through agonist activity at the D1-D2 receptor heteromer. For example, the D1R agonists SKF 81297 and SKF 38393 are still often employed as "selective" D1R agonists, despite evidence demonstrating their ability to induce behavioral and neurochemical effects characteristic of dopamine D1-D2 heteromer activation, such as grooming and activation of PLC leading to intracellular calcium release (Molloy and Waddington, 1987; Undie and Friedman, 1990; Undie et al., 1994; Rashid et al., 2007). Furthermore, the D5 receptor has also been shown to induce a calcium signal through PLC activation or extracellular calcium influx (So et al., 2009), further confounding the pharmacological profile of these agonists. As such, the interpretation of both past and future results should take into account that activation of individual dopamine receptors by these compounds most likely occurs in tandem with D1-D2 receptor heteromer activation on the physiologically relevant subset neurons coexpressing both the D1R and D2R. The appropriate selection of dopaminergic drugs is therefore essential to effectively isolate the specific complex, or signaling pathway, under investigation.

\section{CONCLUDING REMARKS}

For the most part, studies agree that the D1R and D2R are predominantly segregated to discrete populations of MSNs in striatum and, additionally, that functional cross-talk between the D1R and $\mathrm{D} 2 \mathrm{R}$ is critical in mediating some of the physiological effects of dopamine, such as the synergistic effects of D1R/D2R activation on immediate early gene expression. However, there is also an abundance of evidence showing that a proportion of MSNs in striatum coexpresses the D1R and D2R, and the physiological importance of these neurons is now beginning to become apparent. Specifically, unlike D1R-only and D2R-only striatal MSNs, D1R/D2R-coexpressing striatal projection neurons have been reported to terminate in regions within both the striatonigral and striatopallidal pathways, as well as regions containing dopamine 
neuronal cell bodies. These findings, as well as the demonstration of $\mathrm{D} 1 \mathrm{R} / \mathrm{D} 2 \mathrm{R}$ coexpression at presynaptic terminals, indicate that receptor coexpression may have a unique physiological function at a local level, via MSN-MSN synaptic connections, as well as distal effects through their efferent projections (Figure 4). This would likely contribute to the regulation of thalamic neurotransmission, perhaps with the purpose of maintaining homeostatic balance between the direct and indirect pathways. It is possible that this may occur, at least in part, through the regulation of postsynaptic glutamate transmission in the basal ganglia (Stefani et al., 1998), as these neurons exhibit a unique expression phenotype of the AMPA GluA subunits. In addition, these D1R/D2R MSNs also express the dopamine D1-D2 receptor heteromer, a novel receptor complex that links dopamine receptor activation directly to calcium signaling and BDNF production in vivo. Together, the evidence indicates that MSNs coexpressing the D1R and D2R in the basal ganglia embody a physiologically relevant, and functionally active, subset of neurons. We propose that D1R/D2R-coexpressing MSNs represent a third major dopamine receptor neuronal pathway, in addition to the striatonigral and striatopallidal pathways, with the potential to provide a novel approach to drug discovery in basal ganglia disorders.

\section{ACKNOWLEDGMENTS}

This work was supported by a grant (DA007223) from the National Institute on Drug Abuse (to Susan R. George and Brian F. O'Dowd), and a Canadian Institute of Health Research Fellowship (to Melissa L. Perreault). Susan R. George holds a Canada Research Chair in Molecular Neuroscience.

\section{REFERENCES}

Aizman, O., Brismar, H., Uhlen, P., Zettergren, E., Levey, A. I., Forssberg, H., Greengard, P., and Aperia, A. (2000). Anatomical and physiological evidence for D1 and D2 dopamine receptor colocalization in neostriatal neurons. Nat. Neurosci. 3 , 226-230.

Anderson, K. D., and Reiner, A. (1990). Extensive co-occurrence of substance $\mathrm{P}$ and dynorphin in striatal projection neurons: an evolutionarily conserved feature of basal ganglia organization. J. Comp. Neurol. 295, 339-369.

Anderson, S. M., Famous, K. R., SadriVakili, G., Kumaresan, V., Schmidt, H. D., Bass, C. E., Terwilliger, E. F., Cha, J. H., and Pierce, R. C. (2008). CaMKII: a biochemical bridge linking accumbens dopamine and glutamate systems in cocaine seeking. Nat. Neurosci. 11, 344-353.

Andringa, G., Drukarch, B., Leysen, J. E., Cools, A. R., and Stoof, J. C. (1999). The alleged dopamine D1 receptor agonist SKF 83959 is a dopamine D1 receptor antagonist in primate cells and interacts with other receptors. Eur. J. Pharmacol. 364, 33-41.

Arnt, J., Hyttel, J., and Sanchez, C. (1992). Partial and full dopamine D1 receptor agonists in mice and rats: relation between behavioural effects and stimulation of adenylate cyclase activity in vitro. Eur. J. Pharmacol. 213, 259-267.

Aubert, I., Ghorayeb, I., Normand, E., and Bloch, B. (2000). Phenotypical characterization of the neurons expressing the D1 and D2 dopamine receptors in the monkey striatum. J. Comp. Neurol. 418, 22-32.

Bertran-Gonzalez, J., Bosch, C., Maroteaux, M., Matamales, M., Herve, D., Valjent, E., and Girault, J. A. (2008). Opposing patterns of signaling activation in dopamine D1 and D2 receptor-expressing striatal neurons in response to cocaine and haloperidol. J. Neurosci. 28, 5671-5685.

Besson, M. J., Graybiel, A. M., and Quinn, B. (1990). Co-expression of neuropeptides in the cat's striatum: an immunohistochemical study of substance $\mathrm{P}$, dynorphin B and enkephalin. Neuroscience 39, 33-58.

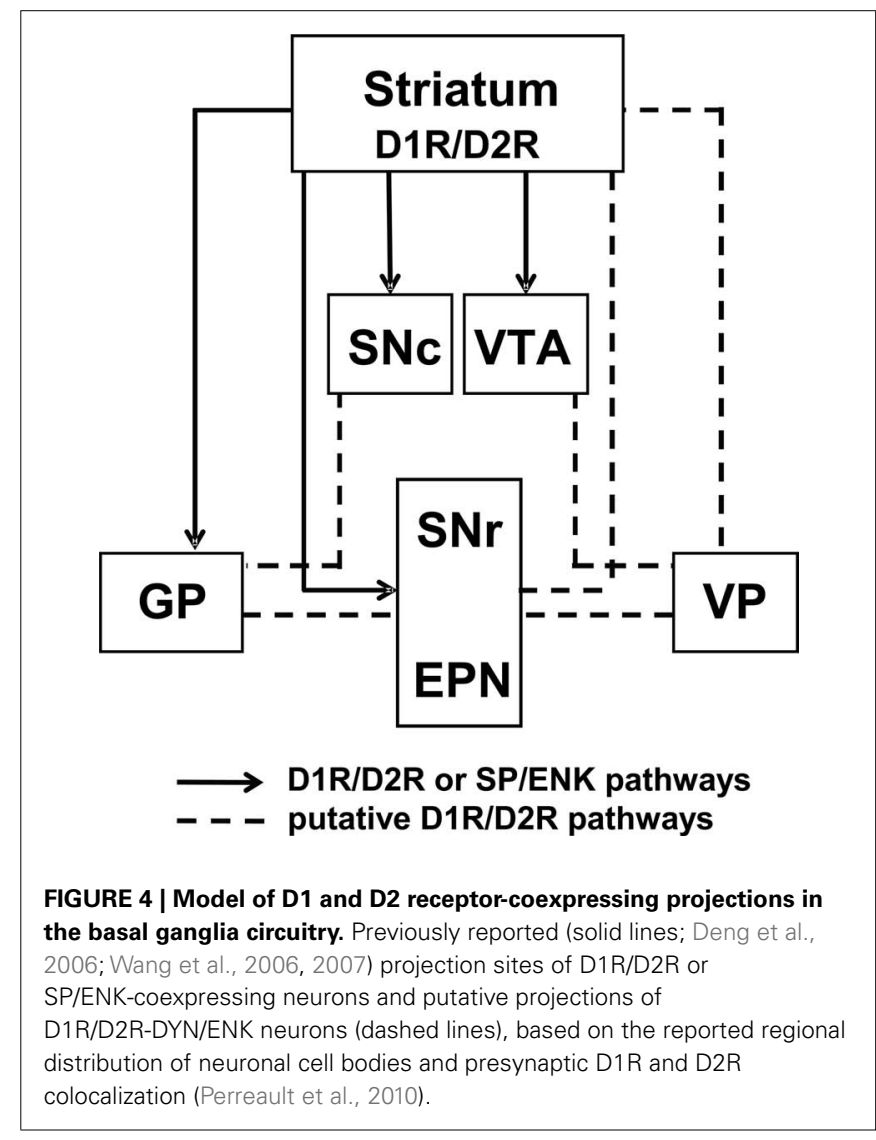

Calabresi, P., Maj, R., Mercuri, N. B., and Bernardi, G. (1992). Coactivation of D1 and D2 dopamine receptors is required for long-term synaptic depression in the striatum. Neurosci. Lett. 142, 95-99.

Capper-Loup, C., Canales, J. J., Kadaba, N., and Graybiel, A. M. (2002). Concurrent activation of dopamine D1 and $\mathrm{D} 2$ receptors is required to evoke neural and behavioral phenotypes of cocaine sensitization. J. Neurosci. 22, 6218-6227.

Carlino, D., Leone, E., Di Cola, F., Baj, G., Marin, R., Dinelli, G., Tongiorgi, E., and De Vanna, M. (2011). Low serum truncated-BDNF isoform correlates with higher cognitive impairment in schizophrenia. $J$. Psychiatr. Res. 45, 273-279.

Chen, Q., Veenman, L., Knopp, K., Yan, Z., Medina, L., Song, W. J., Surmeier, D. J., and Reiner, A. (1998). Evidence for the preferential localization of glutamate receptor-1 subunits of AMPA receptors to the dendritic spines of medium spiny neurons in rat striatum. Neuroscience 83 , 749-761.

DeBoer, P., and Abercrombie, E. D. (1996). Physiological release of striatal acetylcholine in vivo: modulation by D1 and D2 dopamine receptor subtypes. J. Pharmacol. Exp. Ther. 277, 775-783.

Delgado, A., Sierra, A., Querejeta, E., Valdiosera, R. F., and Aceves, J. (2000). Inhibitory control of the GABAergic transmission in the rat neostriatum by D2 dopamine receptors. Neuroscience 95, 1043-1048.

Deng, Y. P., Lei, W. L., and Reiner, A. (2006). Differential perikaryal localization in rats of D1 and D2 dopamine receptors on striatal projection neuron types identified by retrograde labeling. J. Chem. Neuroanat. 32, 101-116.

Desai, R. I., Terry, P., and Katz, J. L. (2005). A comparison of the locomotor stimulant effects of D1like receptor agonists in mice. Pharmacol. Biochem. Behav. 81, 843-848.

Deveney, A. M., and Waddington, J. L. (1995). Pharmacological characterization of behavioural responses to SK\&F 83959 in relation to 'D1-like' dopamine receptors not linked to adenylyl cyclase. Br. J. Pharmacol. 116, 2120-2126. 
Di Chiara, G., Morelli, M., and Consolo, S. (1994). Modulatory functions of neurotransmitters in the striatum: $\mathrm{ACh} /$ dopamine/NMDA interactions. Trends Neurosci. 17, 228-233.

Dziedzicka-Wasylewska, M., FaronGorecka, A., Andrecka, J., Polit, A., Kusmider, M., and Wasylewski, Z. (2006). Fluorescence studies reveal heterodimerization of dopamine D1 and D2 receptors in the plasma membrane. Biochemistry 45, 8751-8759.

Featherstone, R. E., Kapur, S., and Fletcher, P. J. (2007). The amphetamine-induced sensitized state as a model of schizophrenia. Prog. Neuropsychopharmacol. Biol. Psychiatry 31, 1556-1571.

Geldwert, D., Norris, J. M., Feldman, I. G., Schulman, J. J., Joyce, M. P., and Rayport, S. (2006). Dopamine presynaptically and heterogeneously modulates nucleus accumbens medium-spiny neuron GABA synapses in vitro. $\mathrm{BMC} \mathrm{Neu-}$ rosci. 7, 53-69. doi: 10.1186/14712202-7-53

Gerfen, C. R., Engber, T. M., Mahan, L. C., Susel, Z., Chase, T. N., Monsma, F. J. Jr., and Sibley, D. R. (1990). D1 and D2 dopamine receptorregulated gene expression of striatonigral and striatopallidal neurons. Science 250, 1429-1432.

Gerfen, C. R., Keefe, K. A., and Gauda, E. B. (1995). D1 and D2 dopamine receptor function in the striatum: coactivation of $\mathrm{D} 1-$ and D2-dopamine receptors on separate populations of neurons results in potentiated immediate early gene response in D1-containing neurons. J. Neurosci. 15, 8167-8176.

Gerfen, C. R., and Young, W. S. III. (1988). Distribution of striatonigral and striatopallidal peptidergic neurons in both patch and matrix compartments: an in situ hybridization histochemistry and fluorescent retrograde tracing study. Brain Res. 460, 161-167.

Gnanalingham, K. K., Hunter, A. J., Jenner, P., and Marsden, C. D. (1995). Stimulation of adenylate cyclase activity by benzazepine $\mathrm{D}$ 1 dopamine agonists with varying efficacies in the 6-hydroxydopamine lesioned rat-relationship to circling behaviour. Biochem. Pharmacol. 49, 1185-1193.

Guzman, J. N., Hernandez, A., Galarraga, E., Tapia, D., Laville, A., Vergara, R., Aceves, J., and Bargas, J. (2003). Dopaminergic modulation of axon collaterals interconnecting spiny neurons of the rat striatum. $J$. Neurosci. 23, 8931-8940.

Hasbi, A., Fan, T., Alijaniaram, M., Nguyen, T., Perreault, M. L., O'Dowd, B. F., and George, S. R. (2009). Calcium signaling cascade links dopamine D1-D2 receptor heteromer to striatal BDNF production and neuronal growth. Proc. Natl. Acad. Sci. U.S.A. 106, 21377-21382.

Hu, X. T., Wachtel, S. R., Galloway, M. P., and White, F. J. (1990). Lesions of the nigrostriatal dopamine projection increase the inhibitory effects of D1 and D2 dopamine agonists on caudate-putamen neurons and relieve D2 receptors from the necessity of D1 receptor stimulation. J. Neurosci. 10, 2318-2329.

Hyttel, J. (1978). Effects of neuroleptics on $3 \mathrm{H}$-haloperidol and $3 \mathrm{H}-\mathrm{cis}(\mathrm{Z})-$ flupenthixol binding and on adenylate cyclase activity in vitro. Life Sci. 23, 551-555.

Issa, G., Wilson, C., Terry, A. V. Jr., and Pillai, A. (2010). An inverse relationship between cortisol and BDNF levels in schizophrenia: data from human postmortem and animal studies. Neurobiol. Dis. 39, 327-333.

Jin, L. Q., Goswami, S., Cai, G., Zhen, X., and Friedman, E. (2003). SKF83959 selectively regulates phosphatidylinositol-linked D1 dopamine receptors in rat brain. $J$. Neurochem. 85, 378-386.

Jindal, R. D., Pillai, A. K., Mahadik, S. P., Eklund, K., Montrose, D. M., and Keshavan, M. S. (2010). Decreased BDNF in patients with antipsychotic naive first episode schizophrenia. Schizophr. Res. 119, 47-51.

Keefe, K. A., and Gerfen, C. R. (1995). D1-D2 dopamine receptor synergy in striatum: effects of intrastriatal infusions of dopamine agonists and antagonists on immediate early gene expression. Neuroscience 66, 903-913.

LaHoste, G. J., Henry, B. L., and Marshall, J. F. (2000). Dopamine D1 receptors synergize with $\mathrm{D} 2$, but not $\mathrm{D} 3$ or D4, receptors in the striatum without the involvement of action potentials. J. Neurosci. 20, 6666-6671.

LaHoste, G. J., Yu, J., and Marshall, J. F. (1993). Striatal Fos expression is indicative of dopamine D1/D2 synergism and receptor supersensitivity. Proc. Natl. Acad. Sci. U.S.A. 90, 7451-7455.

Lee, S. P., So, C. H., Rashid, A. J., Varghese, G., Cheng, R., Lanca, A. J., O'Dowd, B. F., and George,
S. R. (2004). Dopamine D1 and D2 receptor Co-activation generates a novel phospholipase C-mediated calcium signal. J. Biol. Chem. 279, 35671-35678.

Lester, J., Fink, S., Aronin, N., and DiFiglia, M. (1993). Colocalization of D1 and D2 dopamine receptor mRNAs in striatal neurons. Brain Res. 621, 106-110.

Lidow, M. S. (2003). Calcium signaling dysfunction in schizophrenia: a unifying approach. Brain Res. Brain Res. Rev. 43, 70-84.

Lin, C. W., Miller, T. R., Witte, D. G., Bianchi, B. R., Stashko, M., Manelli, A. M., and Frail, D. E. (1995). Characterization of cloned human dopamine D1 receptor-mediated calcium release in 293 cells. Mol. Pharmacol. 47, 131-139.

Lobo, M. K., Covington, H. E. III, Chaudhury, D., Friedman, A. K. Sun, H., Damez-Werno, D., Dietz, D. M., Zaman, S., Koo, J. W., Kennedy, P. J., Mouzon, E., Mogri, M., Neve, R. L., Deisseroth, K., Han, M. H., and Nestler, E. J. (2010). Cell type-specific loss of BDNF signaling mimics optogenetic control of cocaine reward. Science 330, 385-390.

Matamales, M., Bertran-Gonzalez, J., Salomon, L., Degos, B., Deniau, J. M., Valjent, E., Herve, D., and Girault, J. A. (2009). Striatal medium-sized spiny neurons: identification by nuclear staining and study of neuronal subpopulations in BAC transgenic mice. PLoS ONE 4, e4770. doi: 10.1371/journal.pone.0004770

McGinty, J. F., Whitfield, T. W. Jr., and Berglind, W. J. (2010). Brain-derived neurotrophic factor and cocaine addiction. Brain Res. 1314, 183-193.

Meador-Woodruff, J. H., Mansour, A., Healy, D. J., Kuehn, R., Zhou, Q. Y., Bunzow, J. R., Akil, H., Civelli, O., and Watson, S. J. Jr. (1991). Comparison of the distributions of D1 and D2 dopamine receptor mRNAs in rat brain. Neuropsychopharmacology 5, 231-242.

Mizuno, T., Schmauss, C., and Rayport, S. (2007). Distinct roles of presynaptic dopamine receptors in the differential modulation of the intrinsic synapses of medium-spiny neurons in the nucleus accumbens. $B M C$ Neurosci. 8, 8-22. doi: 10.1186/14712202-8-8

Molloy, A. G., and Waddington, J. L. (1987). Assessment of grooming and other behavioural responses to the D-1 dopamine receptor agonist SK\&F 38393 and its R- and S-enantiomers in the intact adult rat. Psychopharmacology (Berl.) 92, 164-168.

Neumeyer, J. L., Kula, N. S., Bergman, J., and Baldessarini, R. J. (2003). Receptor affinities of dopamine D1 receptor-selective novel phenylbenzazepines. Eur. J. Pharmacol. 474, 137-140.

Ng, J., Rashid, A. J., So, C. H., O'Dowd, B. F., and George, S. R. (2010). Activation of calcium/calmodulindependent protein kinase IIalpha in the striatum by the heteromeric D1-D2 dopamine receptor complex. Neuroscience 165, 535-541.

Novak, G., and Seeman, P. (2010). Hyperactive mice show elevated D2(High) receptors, a model for schizophrenia: calcium/calmodulindependent kinase II alpha knockouts. Synapse 64, 794-800.

Onali, P., Olianas, M. C., and Gessa, G. L. (1985). Characterization of dopamine receptors mediating inhibition of adenylate cyclase activity in rat striatum. Mol. Pharmacol. 28, 138-145.

Panchalingam, S., and Undie, A. S. (2001). SKF83959 exhibits biochemical agonism by stimulating [(35)S]GTP gamma S binding and phosphoinositide hydrolysis in rat and monkey brain. Neuropharmacology 40, 826-837.

Penny, G. R., Afsharpour, S., and Kitai, S. T. (1986). The glutamate decarboxylase-, leucine enkephalin-, methionine enkephalin- and substance P-immunoreactive neurons in the neostriatum of the rat and cat: evidence for partial population overlap. Neuroscience 17, 1011-1045.

Perreault, M. L., Hasbi, A., Alijaniaram, M., Fan, T., Varghese, G., Fletcher, P. J., Seeman, P., O'Dowd, B. F., and George, S. R. (2010). The dopamine D1-D2 receptor heteromer localizes in dynorphin/enkephalin neurons: increased high affinity state following amphetamine and in schizophrenia. J. Biol. Chem. 285, 36625-36634.

Piomelli, D., Pilon, C., Giros, B., Sokoloff, P., Martres, M. P., and Schwartz, J. C. (1991). Dopamine activation of the arachidonic acid cascade as a basis for D1/D2 receptor synergism. Nature 353, 164-167.

Rashid, A. J., So, C. H., Kong, M. M., Furtak, T., El-Ghundi, M., Cheng, R., O'Dowd, B. F., and George, S. R. (2007). D1-D2 dopamine receptor heterooligomers with unique pharmacology are coupled to rapid activation of $\mathrm{Gq} / 11$ in the striatum. Proc. Natl. Acad. Sci. U.S.A. 104, 654-659. 
Reiner, A., Medina, L., and Haber, S. N. (1999). The distribution of dynorphinergic terminals in striatal target regions in comparison to the distribution of substance P-containing and enkephalinergic terminals in monkeys and humans. Neuroscience 88, 775-793.

Shetreat, M. E., Lin, L., Wong, A. C., and Rayport, S. (1996). Visualization of D1 dopamine receptors on living nucleus accumbens neurons and their colocalization with D2 receptors. J. Neurochem. 66, 1475-1482.

Shuen, J. A., Chen, M., Gloss, B., and Calakos, N. (2008). DrdlatdTomato BAC transgenic mice for simultaneous visualization of medium spiny neurons in the direct and indirect pathways of the basal ganglia. J. Neurosci. 28, 2681-2685.

So, C. H., Varghese, G., Curley, K. J., Kong, M. M., Alijaniaram, M., Ji, X., Nguyen, T., O'Dowd B, F., and George, S. R. (2005). D1 and D2 dopamine receptors form heterooligomers and cointernalize after selective activation of either receptor. Mol. Pharmacol. 68, 568-578.

So, C. H., Verma, V., Alijaniaram, M., Cheng, R., Rashid, A. J., O’Dowd, B. F., and George, S. R. (2009). Calcium signaling by dopamine D5 receptor and D5-D2 receptor heterooligomers occurs by a mechanism distinct from that for dopamine D1D2 receptor hetero-oligomers. Mol. Pharmacol. 75, 843-854.

Stefani, A., Chen, Q., Flores-Hernandez, J., Jiao, Y., Reiner, A., and Surmeier, D. J. (1998). Physiological and molecular properties of AMPA/Kainate receptors expressed by striatal medium spiny neurons. Dev. Neurosci. 20, 242-252.

Surmeier, D. J., Eberwine, J., Wilson, C. J., Cao, Y., Stefani, A., and Kitai, S. T. (1992). Dopamine receptor subtypes colocalize in rat striatonigral neurons. Proc. Natl. Acad. Sci. U.S.A. 89, 10178-10182.

Surmeier, D. J., Song, W. J., and Yan, Z. (1996). Coordinated expression of dopamine receptors in neostriatal medium spiny neurons. J. Neurosci. 16, 6579-6591.

Undie, A. S., and Friedman, E. (1990). Stimulation of a dopamine D1 receptor enhances inositol phosphates formation in rat brain. J. Pharmacol. Exp. Ther. 253, 987-992.

Undie, A. S., Weinstock, J., Sarau, H. M., and Friedman, E. (1994). Evidence for a distinct D1-like dopamine receptor that couples to activation of phosphoinositide metabolism in brain. J. Neurochem. 62, 2045-2048.

Valjent, E., Bertran-Gonzalez, J., Herve, D., Fisone, G., and Girault, J. A. (2009). Looking BAC at striatal signaling: cell-specific analysis in new transgenic mice. Trends Neurosci. 32, 538-547.

Verma, V., Hasbi, A., O'Dowd, B. F., and George, S. R. (2010). Dopamine D1D2 receptor Heteromer-mediated calcium release is desensitized by D1 receptor occupancy with or without signal activation: dual functional regulation by $\mathrm{G}$ protein-coupled receptor kinase 2. J. Biol. Chem. 285, 35092-35103.

Vorobjev, V. S., Sharonova, I. N., Haas, H. L., and Sergeeva, O. A. (2000). Differential modulation of AMPA receptors by cyclothiazide in two types of striatal neurons. Eur. J. Neurosci. 12, 2871-2880.

Waddington, J. L., Daly, S. A., Downes, R. P., Deveney, A. M., McCauley, P. G., and O'Boyle, K. M. (1995). Behavioural pharmacology of ' $\mathrm{D}$ 1-like' dopamine receptors: further subtyping, new pharmacological probes and interactions with 'D-2-like' receptors. Prog. Neuropsychopharmacol. Biol. Psychiatry 19, 811-831.
Walters, J. R., Bergstrom, D. A., Carlson, J. H., Chase, T. N., and Braun, A. R. (1987). D1 dopamine receptor activation required for postsynaptic expression of D2 agonist effects. Science 236, 719-722.

Wang, H. B., Deng, Y. P., and Reiner, A. (2007). In situ hybridization histochemical and immunohistochemical evidence that striatal projection neurons co-containing substance $\mathrm{P}$ and enkephalin are overrepresented in the striosomal compartment of striatum in rats. Neurosci. Lett. 425 , 195-199.

Wang, H. B., Laverghetta, A. V., Foehring, R., Deng, Y. P., Sun, Z., Yamamoto, K., Lei, W. L., Jiao, Y. and Reiner, A. (2006). Single-cell RT-PCR, in situ hybridization histochemical, and immunohistochemical studies of substance $\mathrm{P}$ and enkephalin co-occurrence in striatal projection neurons in rats. J. Chem. Neuroanat. 31, 178-199.

Wang, L., Lv, Z., Hu, Z., Sheng, J., Hui, B., Sun, J., and Ma, L. (2010). Chronic cocaine-induced $\mathrm{H} 3$ acetylation and transcriptional activation of CaMKIIalpha in the nucleus accumbens is critical for motivation for drug reinforcement. Neuropsychopharmacology 35, 913-928.

Weickert, C. S., Hyde, T. M., Lipska, B. K., Herman, M. M., Weinberger, D. R., and Kleinman, J. E. (2003). Reduced brain-derived neurotrophic factor in prefrontal cortex of patients with schizophrenia. Mol. Psychiatry 8, 592-610.

White, F. J., Bednarz, L. M., Wachtel, S. R., Hjorth, S., and Brooderson, R. J. (1988). Is stimulation of both D1 and D2 receptors necessary for the expression of dopamine-mediated behaviors? Pharmacol. Biochem. Behav. 30, 189-193.

White, F. J., and Wang, R. Y. (1986). Electrophysiological evidence for the existence of both D-1 and
D-2 dopamine receptors in the rat nucleus accumbens. J. Neurosci. 6, 274-280.

Wong, A. C., Shetreat, M. E., Clarke, J. O., and Rayport, S. (1999). D1and D2-like dopamine receptors are co-localized on the presynaptic varicosities of striatal and nucleus accumbens neurons in vitro. Neuroscience $89,221-233$.

Wong, J., Hyde, T. M., Cassano, H. L., Deep-Soboslay, A., Kleinman, J. E., and Weickert, C. S. (2010). Promoter Specific Alterations of BDNF mRNA in Schizophrenia. Neuroscience 169, 1071-1084.

Zhen, X., Goswami, S., and Friedman, E. (2005). The role of the phosphatidyinositol-linked D1 dopamine receptor in the pharmacology of SKF83959. Pharmacol. Biochem. Behav. 80, 597-601.

Conflict of Interest Statement: The authors declare that the research was conducted in the absence of any commercial or financial relationships that could be construed as a potential conflict of interest.

Received: 29 April 2011; paper pending published: 11 May 2011; accepted: 16 May 2011; published online: 31 May 2011.

Citation: Perreault ML, Hasbi A, O'Dowd $B F$ and George SR (2011) The dopamine D1-D2 receptor heteromer in striatal medium spiny neurons: evidence for a third distinct neuronal pathway in basal ganglia. Front. Neuroanat. 5:31. doi: 10.3389/fnana.2011.00031

Copyright (c) 2011 Perreault, Hasbi, O'Dowd and George. This is an openaccess article subject to a non-exclusive license between the authors and Frontiers Media SA, which permits use, distribution and reproduction in other forums, provided the original authors and source are credited and other Frontiers conditions are complied with. 